\section{EL INDIVIDUO MODERNO: ENTRE EL ANIMAL INDUSTRIOSO Y LA LIBERTAD POLIITICA ${ }^{1}$}

\author{
María Luciana Cadahia \\ Departamento de Filosofía. Universidad Autónoma de Madrid. \\ Becaria FPU-UAM y Residencia CSIC \\ Calle Pinar 21, Residencia CSIC, 28006 Madrid \\ luciana.cadahia@gmail.com
}

\section{THE MODERN INDIVIDUAL; BETWEEN THE INDUSTRIOUS ANIMAL AND THE POLITICAL FREEDOM}

\begin{abstract}
In this article I deal with the paradoxes that aroused after the emergence of individualism in liberal democracies. In order to articulate these paradoxes, I'll take the reflections Tocqueville made in Democracy in America about this subject so as to reflect on how the connections between individual and democracy were made. Firstly, l examine the inconveniences of the discourse of deliberate democracy because I want to break up the existing link between the concept of liberalism and the concept of democracy. On one side, I show the impossibility to think democracy from an original model. I examine the impossibility to fix a necessary link between democracy and liberalism. I intend to describe the assumption that supports this whole theory: considering the individual as the axis around whom the discourse is built up.. Finally, I consider the importance of thinking a contingent link between democracy and liberalism to take up again the concept of political freedom as a necessary matter for activating the revolutionary moment of the democratic discourse.
\end{abstract}

KEY WORDS: Democracy; freedom; political freedom; individual freedom; liberalism; individual.

\section{I}

Desde hace algunas décadas experimentamos una asidua recuperación del pensamiento de Tocqueville ${ }^{2}$ en el ámbito de la sociología, la historia y la filosofía. Es a partir de sus reflexiones en torno a la democracia y la revolución que abre una brecha de inteligibilidad para trabajar hoy la democracia como problema a pensar. Además del objeto de investigación abordado por Tocqueville también interesa prestar atención a la manera en que ha trabajado esta cuestión. Es decir, al igual que sus contemporáneos, este autor piensa en los términos de la filosofía de la historia, pero con la particularidad de que en sus reflexiones no hay una clausura de la misma, dado que el acontecimiento de la democracia se torna un horizonte abierto, inescrutable
RESUMEN: En este artículo trabajo las paradojas vinculadas al surgimiento de la figura del individualismo dentro de las democracias liberales. Para articular estas paradojas, tomaré como guía las reflexiones llevadas a cabo por Tocqueville en La Democracia en América. Esto me permitirá pensar de qué modo se han establecido las conexiones entre individuo y democracia. En primer lugar, estudiaré algunos inconvenientes del discurso de la Democracia deliberativa, puesto que desarticularé el vínculo entre el concepto de liberalismo y el concepto de democracia alli presente. Por un lado, Mostraré la imposibilidad para pensar la democracia a partir de un modelo originario. Por otro, examinaré la imposibilidad de fijar un enlace necesario entre democracia y liberalismo. En segundo lugar, examinaré los límites del discurso neoliberal. Intentaré caracterizar los problemas del supuesto que sostiene toda la teoria: el individuo como eje que articula el discurso. Finalmente, desarrollaré la importancia de pensar un vínculo contingente entre estos dos términos, con el objeto de recuperar el concepto de libertad política como elemento imprescindible para reactivar el momento revolucionario del discurso democrático.

PALABRAS CLAVE: Democracia; libertad; libertad politica; libertad individual; liberalismo; individuo.

e impredecible. Por citar sólo un ejemplo, esta actitud abierta hacia el porvenir la encontramos el segundo tomo de La Democracia en América, donde nos dice:

Yo mismo busco en vano una expresión que reproduzca y encierre exactamente la idea que me formo; las antiguas palabras de despotismo y tiranía no son adecuadas. La cosa es nueva; es preciso entonces tratar de definirla, ya que no puedo nombrarla ${ }^{3}$.

Esta manera de abordar la democracia toma distancia de una actitud normativa. Si atendemos a las reflexiones actuales sobre la democracia, encontramos dos actitudes bien distintas. Hay pensadores como Habermas o Rawls que intentan construir un modelo normativo que pueda ser 
aplicado a la realidad y de ese modo resolver los conflictos sociales. A diferencia de esta actitud formalista que trata de aplicar desde fuera una serie de categorías para ordenar y anular el conflicto, hay otra tendencia que parte de la misma conflictividad social como un aspecto irreductible desde el cual pensar la democracia. Aquí encontramos pensadores como Rancière o Laclau y la particularidad de estas propuestas es que no asumen la necesidad de elaborar un modelo democrático sino que consideran a la democracia como una forma social, un modo en que se manifiestan y negocian los disensos. A este respecto, la reconsideración de los textos de Tocqueville contribuye a enriquecer esta segunda clave de lectura, puesto que en vez de plantear los avances y retrocesos de la democracia a partir de la visión que se debe tener de ella, se parte de la necesidad de pensar cómo ésta ha llegado a identificarse de una determinada manera. Es decir, qué idea de democracia está efectivamente funcionando como horizonte de sentido para pensar nuestra actualidad y cuáles son los problemas que atañen a tal modo de cristalización.

En línea de continuidad con la actitud de Tocqueville, entonces, no abogamos por la construcción de un modelo que resuelva las fisuras del acontecimiento democrático, por el contario, nos adentramos en ellas para tratar de pensar a partir de ahí su carácter indeterminado e irresoluble, y aproximarnos a la cosa misma de lo político. A este respecto, se parte del supuesto de que la forma de racionalidad, que anuda una determinada idea de democracia, no se corresponde con la realización de un ideal sino con el lugar de trabajo de un problema. La principal característica que descubre Tocqueville es la culminación del largo proceso de igualación de condiciones entre los hombres, pero más precisamente la expansión de esta igualdad a todo los ámbitos de la vida humana. La constatación de este fenómeno obliga a pensar qué significa este acontecimiento.

\section{II}

Al concebir la igualdad de condiciones entre los hombres como el gran motor de la revolución de la sociedad moderna, Tocqueville no hace más que establecer un marco de inteligibilidad para pensar el cambio social que ha implicado el advenimiento de la democracia ${ }^{4}$. Oscilante con respecto a este acontecimiento, en los últimos capítulos de La Democracia en América nos arroja a una paradoja vinculada con la emergencia de la figura del individuo moderno, a saber: a la vez que separa a los hombres entre sí los vuelve una masa indiferenciada y uniforme. Mientras que en el ámbito de la vida privada emerge la figura del individuo con el despliegue de sus capacidades y libertades propias, esta misma forma de existencia novedosa es la que los aglutina como masa indiferenciada y obediente. El dilema está en que la emergencia y expansión de los distintos ámbitos de la vida privada pareciera ser inversamente proporcional a las posibilidades de intervenir en la constitución de esas formas de vida, quedando sujetados a un dispositivo que...

(...) no destruye voluntades, las ablanda, las doblega y las dirige; rara vez obliga a obrar, se opone a que se obre; no mata, impide nacer; no tiraniza, mortifica, reprime, enerva, apaga, embrutece y reduce al cabo a toda nación a rebaño de animales, tímidos e industriosos cuyo pastor es el gobierno ${ }^{5}$.

A continuación añade que esta clase de servidumbre descansa en dos pasiones contrapuestas, por un lado, la necesidad de ser conducidos y, por otro, el deseo de permanecer libres. Ante el intento de satisfacer ambas pasiones se produce una extraña tensión que da por resultado una forma de libertad externa, en la que los hombres al confundir capacidad de elección con la soberanía del pueblo, se creen libres por elegir un representante que los tutele. De este modo, los hombres se limitan a comportarse como "animales industriosos" porque descubren que en el interior de sí mismos lo único que opera es la voluntad de obediencia como ciega necesidad, viéndose incapaces de obrar de otra manera.

Uno de los mayores peligros de la experiencia democrática es la constatación de una libertad externa que en vez de hacer libres a los hombres suscita la paradójica voluntad del rebaño y del aislamiento. A partir de esto uno podría preguntarse si la experiencia democrática está destinada a producir sujetos obedientes a esta lógica o si por el contrario esto no descansa en un determinado modo de articularse la democracia y la economía. Si prestamos atención al modo en que ha tenido lugar la experiencia democrática descubrimos su indudable conexión con el liberalismo. 
Los intentos de establecer un modelo deseable para las democracias liberales se encuentran atravesada por dos lógicas irreconciliables. El principio de soberanía del pueblo considerado como principio de igualdad, por un lado, y el principio de libertad identificado como el principio de libertades individuales, por el otro. Con el objeto de conseguir que ambos principios logren algún tipo de convivencia deseable, los precursores de esta actitud parten de la creencia de que es posible ir resolviendo el conflicto mediante un consenso racional -garante de un principio de libertad- en el cual todos los individuos encuentren representadas sus demandas -garantizando asi el ejercicio de la igualdad. Aquí parece mezclarse el discurso democrático con el discurso liberal, puesto que si el pueblo es identificado como la suma de los individuos, la representación debería ser el instrumento que posibilitase a cada uno de ellos el ingreso al ámbito de la política.

A partir de esta manera de entender las cosas, el problema de las democracias actuales es leído como el resultado de una serie de limitaciones que los mecanismos de representación tienen para reflejar los distintos intereses de la comunidad. Por consecuencia, la resolución del conflicto consistiria en ir elaborando un instrumento que incluya a la totalidad de los individuos. Pero si la conquista del consenso racional consiste en proveer de un instrumento de representación adecuado, el éxito de tal empresa implicaría la destrucción del principio de representación, ya que éste dejaría de corresponderse con los intereses particulares para pasar a identificarse con la totalidad.

La meta de articular un instrumento adecuado para la representación, que logre equilibrar los principios de libertad e igualdad, sólo puede funcionar como el ideal regulativo que sostiene todo el edificio del modelo. Es a partir de esta creencia que se espera tomar las decisiones, las cuales tendrán consecuencias prácticas en el momento de organizar la convivencia dentro de una comunidad. En este punto es donde la propuesta comienza a oscurecerse. La posibilidad de una armonía entre el principio de libertad y el principio de igualdad no puede ser perfectamente conciliada.

Más aún, en el texto Debate sobre el liberalismo político, Habermas y Rawls discuten este problema. El debate versa sobre relación entre la libertad individual y la igualdad. $Y$ el desacuerdo está o bien en darle prioridad al principio de una política liberal, en los términos de un principio de justicia que todo individuo racional libremente pueda adherir (conciliación de razones privadas), como en el caso de Rawls; o bien en priorizar el principio democrático de una instancia ideal discursiva de consenso, en los términos de una teoría de la acción y la ética comunicativa (conciliación de razones públicas), en el caso de Habermas ${ }^{6}$.

Este desacuerdo surge porque el ideal regulativo de conciliar el principio de igualdad y el principio de libertad se sostiene sobre la base de una paradoja irresoluble: es la imposibilidad de conciliación entre los dos principios la condición de existencia del ideal. El aspecto criticable de estas propuesta descansa en que si bien el modelo se sostiene a partir de la suposición de que es posible la conciliación o equilibrio entre la libertad individual y la igualdad, no obstante, es esto mismo lo que se torna imposible y lleva, tanto a Rawls como a Habermas, a inclinarse a favor de alguno de estos dos principios en detrimento del otro ${ }^{7}$.

Lo que resulta problemático del modelo en última instancia es la relación que se establece entre esta regulación formal procedimental y las mismas prácticas de los sujetos. Esto es, en el modo en que incide este ideal regulativo (dispositivo democrático) en el momento de sujetar a los individuos y exigirles un determinado tipo de obediencia. Si la regulación de las prácticas se encuentran legitimadas por un ideal imposible, pero al cual aspiramos incansablemente, resulta problemático seguir asumiendo la viabilidad de los logros de aquel modelo que garantizaría la reconciliación entre libertad e igualdad. El mayor inconveniente es que esta regulación procedimental establece una determinada homogenización de las prácticas, bajo el supuesto de que ofrece aquello que no puede realizar. El problema, entonces, es doble, ya que se vuelve difícil determinar cuáles son las razones legítimas que forman parte del consenso racional o de la justicia política, a la vez que esto queda legitimado por un extraño ideal regulativo cuya condición de posibilidad es al mismo tiempo la condición de imposibilidad de su perfecta implementación. Así, detectamos que ese ideal regulativo, necesario e imposible a la vez, establece una partición normativa en las mismas relaciones entre los hombres. Es decir, instaura una división entre las prácticas discursivas que, al identificarse con los principios de diálogo y consenso, quedan legitimadas como aproximaciones a ese ideal, a la vez que censura aquellas prácticas discursivas 
que justamente emergen para abrir o profundizar una determinada tensión dentro del campo de lo político. Dicho de otra manera, y retomando las advertencias de Tocqueville, propicia una homogenización de las conductas, puesto que protege un determinado conjunto de prácticas, a la vez que condena y excluye cualquier otro modo de acción que no se ajuste a la lógica del procedimiento pautado (o consenso racional). De esta manera, la naturaleza conflictiva de la política queda supeditada a un principio que no hace más que volverse irrealizable en el momento mismo de su enunciación. Promete lo que no puede llevar a cabo y por eso mismo no agota sus posibilidades. Y a su vez propicia una voluntad de obediencia que veíamos como uno de los principales problemas que explicitamos al inicio del texto.

\section{III}

Frente a este intento de articular teóricamente un vínculo entre democracia y liberalismo, encontramos una serie de liberales conservadores que si bien no renuncian al uso del término democracia, al vaciarlo de todo contenido político hacen de éste un mero concepto técnico, al servicio de una idea externa de libertad. El presupuesto que está a la base de este modelo teórico es la figura del individuo como propietario. A partir de esto el liberalismo conservador pretende romper el vínculo entre liberalismo y democracia y para ello establece una disociación entre libertad y política. El concepto de libertad se reduce a libertad individual. Se concibe una idea negativa de libertad y ser libre se reduce a una no intervención en mi campo de conducta. La libertad positiva es concebida como un atentado contra aquella libertad originaria y fundamental. Se hace de la democracia un mero instrumento procedimental, dado que es concebida "esencialmente (como) un medio, un instrumento utilitario para salvaguardar la paz interna y la libertad individual"8.

Las reflexiones de Tocqueville sobre la figura del individuo son imprescindibles para elaborar una crítica a este segundo modelo teórico. El mayor inconveniente que podemos atribuirle es la expansión de un individualismo ciego en donde los "los ciudadanos salen un momento de la dependencia para elegir a su amo, y luego vuelven a ella"'.
En La Democracia en América, se establece una serie de diferencias y similitudes entre individualismo y egoísmo que pueden ayudar a comprender el problema del surgimiento de la figura del individuo moderno.

El individualismo es una expresión reciente engendrada por una idea nueva (...). El egoísmo es un amor apasionado y exagerado hacia la propia persona que induce al hombre a no referir nada sino a uno mismo y a preferirse en todo. $\mathrm{El}$ individualismo es un sentimiento reflexivo y apacible que induce a cada ciudadano a aislarse (...). El egoísmo nace de un instinto ciego; el individualismo procede de un juicio erróneo (...) origina tanto los defectos del espíritu como en los vicios de la afectividad. El egoísmo seca la fuente de las virtudes; el individualismo, al principio, sólo ciega las virtudes públicas; pero a la larga ataca y destruye todas las otras, y acaba encerrándose en el egoísmo. El egoísmo es un vicio tan viejo como el mundo, y pertenece a cualquier forma de sociedad, (...) el individualismo es propio de las democracias, y amenaza con desarrollarse a medida que las condiciones se igualen ${ }^{10}$.

De aquí se desprende que uno de los problemas más acuciantes del surgimiento de la figura del individuo moderno es la paulatina tendencia a sucumbir en un individualismo ciego. Esta inclinación hacia el individualismo da lugar a dos presupuestos que Tocqueville pone en entre dicho. Frente a la creencia de que el individuo es anterior a toda sociedad, Tocqueville procura señalar que esta idea es un invento de la modernidad, permitiendo así cuestionar el principal presupuesto del que parten algunas teorias sobre la democracia liberal: la preexistencia de los individuos a cualquier lazo social. Es decir, la figura del individuo no es el punto de partida para pensar la organización y edificación de un orden social, puesto que es determinada forma de organización social la que ha dado lugar a la figura del individuo.

La paradoja de asumir el acontecimiento democrático como el triunfo de la emergencia de la libertad individual es que se pierde de vista la dimensión política e histórica de este logro. Se lo asume como un a priori incuestionable, sin prestar atención a la forma que adquiere esta idea de libertad individual. Es decir, se considera que el mero hecho de proteger la figura de la libertad individual basta para que sea deseable en sí misma, cuando de lo que se trata es de pensar en qué medida las formas de organización social orientan y configuran una determinada forma de individuo. 
El liberalismo conservador elabora una hegemonía de la diferencia". Al partir del supuesto de la preexistencia del individuo, emerge una concepción posesiva de la individualidad desde la cual se supone que la libertad de cada uno se reduce a una manifestación y conservación de sí, independientemente del lazo social. Pero paradójicamente se diseña socialmente esta forma de individualidad. El individuo cree que es libre cuando se conserva y protege de la intervención de los demás sobre sí mismo y pierde de vista que esa forma preventiva de actuar es el resultado de un forma social que lo constituye. Cuanto más se aísla el individuo de los demás es cuando mejor se somete al dispositivo de poder de las democracias liberales.

De este modo, los hombres se protegen los unos de los otros y no problematizan el modo en que se configuran socialmente. Este aislamiento generalizado abre las puertas para que los poderes fácticos determinen la manera en que se constituyen las relaciones entre los hombres. Así la libertad individual se reduce a un tipo de libertad externa cómplice con una servidumbre voluntaria, puesto que esta la "servidumbre, reglamentada, benigna apacible, cuyo cuadro acabo de ofrecer, podría combinarse mejor de lo que se piensa comúnmente con algunas de las formas exteriores de la libertad (...)"12.

La libertad externa se vuelve cómplice con una lógica de servidumbre porque:

En efecto, se hace difícil concebir cómo hombres que han renunciado enteramente al hábito de dirigirse a ellos mismos podrian elegir acertadamente a quienes han de conducirles, y no es posible que un gobierno liberal, enérgico y sabio, se establezca con los sufragios de un pueblo de esclavos $^{13}$.

\section{IV}

A lo largo de este escrito hemos trabajado algunos de los aspectos dilemáticos que subyacen a las pretensiones de pensar la democracia en los términos de un modelo democrático cubierto de una lógica procedimental. Hemos visto en qué medida esta lógica empobrece el rasgo propiamente político del acontecimiento democrático y lo subsume a una oikonomia de las conductas de los hombres.
El principal peligro de la reducción del momento político está intimamente vinculado con una animalización de las conductas, puesto que la mera observancia y sumisión al procedimiento "democrático" adormece la potencia de actuar y establecer unas relaciones que trascienda la lógica de la conservación y ejercicio de la libertad individual. Los hombres se limitan a comportarse como "animales industriosos" porque descubren que en el interior de sí mismos lo único que opera es la voluntad de obediencia como ciega necesidad. Si consideramos a la política como aquella instancia en donde lo que está en juego es la potencia misma del actuar, la cual abre a los hombres a otras formas de sensibilidad y existencia, la elaboración de un modelo democrático procedimental tiende a reducir al mínimo el campo de acción de los individuos. La desaparición o reducción del momento de negociación política obtura el surgimiento de aquel espacio de imprevisibilidad e indeterminación que según Tocqueville caracterizó el acontecimiento democrático.

Por tanto, reorientar el problema de la democracia en los términos de un acontecimiento abierto e indeterminado contribuye, por un lado, a pensar la democracia como una experiencia en constante tensión, un lugar de constante negociación política. $Y$, por otro, a recoger el momento democrático como el lugar del trabajo de un problema. De lo que se trata es de pensar el problema de la libertad en su dimensión política, cuya práctica no limite a una capa externa que protege el reducido ámbito privado de los individuo y sus elecciones singulares para el consumo, sino más bien, potencie el ejercicio de resistencia a un tipo de gobierno que hace de los hombres meros útiles administrables en la economía de la vida.

Esta forma particular de tiranía que se llama despotismo democrático, de la que la Edad Media no tenía, les es familiar a los economistas. No más jerarquías en la sociedad, ni separación de clases, ni rangos fijos: sino un pueblo compuesto por individuos casi semejantes y enteramente iguales, esa masa confusa reconocida como el único soberano legítimo, pero cuidosamente privada de todas las facultades que pudieran permitirle dirigir o incluso vigilar por sí misma su gobierno ${ }^{14}$.

La paradoja a la que nos arroja Tocqueville, entonces, es intrínseca a la emergencia de la figura moderna del individuo, puesto que aquello mismo que separa a los hombres entre

ARBOR Vol. 187750 julio-agosto [2011] 733-739 ISSN: 0210-1963

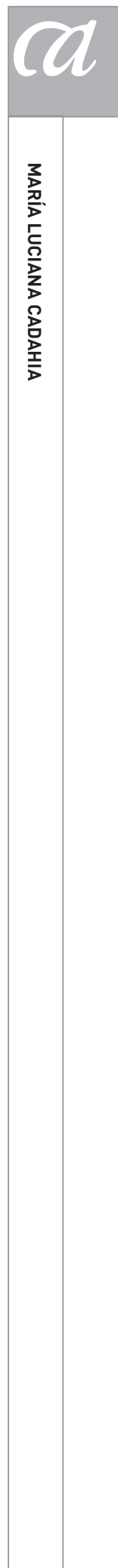

737 
sí en la esfera privada los vuelve una masa indiferenciada en el terreno del gobierno. Mientras que en el ámbito de la vida privada emerge la figura del individuo con el despliegue de sus capacidades y libertades propias, esta misma forma de existencia novedosa es la que los aglutina como masa indiferenciada y obediente a un amo. El dilema está en que la emergencia y expansión de los distintos ámbitos de la vida privada pareciera ser inversamente proporcional a las posibilidades de intervenir en el modo en que nos gobernamos a nosotros mismos y a los demás.

En efecto, se hace difícil concebir cómo hombres que han renunciado enteramente al hábito de dirigirse a ellos mismos podrian elegir acertadamente a quienes han de conducirles, y no es posible que un gobierno liberal, enérgico y sabio, se establezca con los sufragios de un pueblo de esclavos ${ }^{15}$.

El surgimiento progresivo del individuo como figura generadora de lo social, por tanto, es el legado que nos ha dejado Tocqueville para pensar nuestro presente. Alli resuena una y otra vez la cuestión misma de lo político, puesto que es desde ahí donde se dirimen las cegueras y aperturas a que da lugar el acontecimiento democrático. Hemos visto que las propuestas de modelos procedimentales no nos ayudan a pensar el problema, puesto que al operar el individuo como su presupuesto básico éste deviene su propio impensado. Por eso aquí hemos intentado hacer resonar una y otra vez a Tocqueville, ir apropiándonos de su voz para que de ese murmullo surgiese otra vía desde la cual pensar el acontecimiento de la democracia y, en última instancia, a nosotros mismos como parte de ese proceso que aún hoy nos resulta un enigma.

De lo que se trata es de asumir un ejercicio de resistencia a estas formas de configuración de la individualidad contemporánea. Y probablemente el primer paso para ello consista en asumir la idea de que la libertad individual no es el punto de partida desde el cual pensar la articulación de lo social, sino al revés. Esto es, precisar que el individualismo surgido de la figura del individuo democrático es el resultado de un largo proceso histórico y contingente. Y que justamente la condición de posibilidad de su transformación radique en detectar aquellas articulaciones arbitrarias que en nuestra actualidad nos sumen en una práctica de obediencia y sumisión a los dispositivos contemporáneos.

Para ello es imprescindible considerar el problema de la libertad desde su concepción sustantiva, no ya como una no intervención en mi campo de conducta sino como aquellas acciones que contribuyen a la construcción de la subjetividad, ya sea en el plano individual como colectivo.

De esta manera se vuelve imprescindible estudiar, junto a los clásicos como Tocqueville, de qué manera nuestra historia determina nuestro presente, lo que hoy somos, y cómo es posible deshacernos de aquellas determinaciones históricas que en vez de contribuir al trabajo indefinido de la libertad moldea una voluntad obediente y sumisa a los dictámenes de la economía y el consumo de placeres privados.

\section{NOTAS}

1 Este artículo forma parte de las investigaciones realizadas en el marco del proyecto de investigación "Pensar Europa: Democracia y hegemonía en la era tecnológica".

2 Cfr. Rosanvallon, Pierre: "Histoire du mot démocratie à l'époque moderne", en La Pensée Politique, 1. Paris, Gallimard-Le Seuil, 2003, pp. 11-29.

Recibido: 3 de junio de 2010 Aceptado: 13 de junio de 2011
3 Tocqueville, Alexis de: La democracia en América. Vol. 2, Madrid, Alianza, 1980, p. 266.
4 Cfr. Furet, François: "El nacimiento de un paradigma: Tocqueville y el viaje a América (1823-1831) en Lecturas de Tocqueville, Madrid, Siglo XXI, 2007, pp. 43-64.

5 Tocqueville, Alexis: La democracia en América. Vol. 2, Madrid, Alianza, 1980, p. 269.

6 Aqui se recogen una serie de debates entre ambos filósofos, donde si bien se definen ciertos horizontes de problemas comunes; no obstante, cada uno de ellos explicita su inclinación hacia cada una de sus perspectivas (demo- 
cracia, en el caso de Habermas, y el liberalismo, en el caso de Rawls). Cfr. Habermas, Jürgen y Rawls, John: Debate sobre el liberalismo político, Barcelona, Paidós, 1998, pp. 160-161.

7 Para un desarrollo más exhaustivo de la lógica irreconciliable entre ambos principios recomendamos el capítulo Il del libro anteriormente citado de Chantal Mouffe (Mouffe, Chantal: "Carl Schmitt and Paradox of Liberal Democracy" en The Democratic Paradox, op. cit, pp. 36-609) y el discurso inaugural ofrecido por Rosanvallon en el Collège de France (Rosanvallon, Pierre: Pour une histoire conceptuelle du politique, Paris, Seuil, 2002).

8 Hayek, Friedrich: The road to serfdom, op. cit., p. 52.

9 Tocqueville, Alexis: La democracia en América, op. cit., p. 267.

10 Tocqueville, Alexis: La democracia en América. Vol. 2, op cit., p. 89.

11 Cfr.Laclau, Ernesto y Mouffe, Chantal: Hegemonía y estrategia socialista, Buenos Aires, Fondo de cultura económica, 2004, pp. 216-221.

12 Idem., p. 269.

13 Idem., p. 268.

14 Tocqueville, Alexis: El antiguo régimen y la revolución, Madrid, Alianza, 1994, p. 171.

15 lbid., p. 268.

\section{BIBLIOGRAFÍA}

Raymond, Aron (1997): Estudios políticos, México, FCE.

Agamben, Giorgio (2006): Che cos'è un dispositivo, Roma, Nottetempo.

Foucault, Michel (1997): La arqueología del saber, México, Siglo XXI.

- (2001): L'herméneutique du sujet, Paris, Gallimard.
- (2002): Historia de la sexualidad 2-el uso de los placeres, Buenos Aires, Siglo XXI.

- $\quad$ (2008): Le gouvernement de soi et des autres, Paris, Seuil.

Furet, Françoise (1988): La révolution (1770-1880), vol. 4 de la Hisotire de France, Paris, Hachette.

- (1980): Pensar la Revolución Francesa, Barcelona, Petrel.

Habermas, Jürgen, y John Rawls (1998): Debate sobre el liberalismo político, Barcelona, Paidós.

Habermas, Jürgern (1996): Between Facts and Norms: Contributions to a Discourse Theory of Law and Democracy, Cambridge University Press.

- (2003): La ética del discurso y la cuestión de la verdad, Madrid, Paidós.

Friedich Hayek (1944): The road to serfdom, Londres.

Hegel, Georg Wilhem Friedich (1978): Escritos de Juventud, México, FCE.

- (1980): Lecciones sobre la Filosofía de la Historia Universal, Madrid, Alianza.

- (1981): El concepto de religión, Madrid, FCE.

- (2005): Introducción a la filosofía de la Historia Universal, Istmo.

Hyppolite, Jean (1983): Introduction à la Philosophie de Hegel, Paris, Seuil.

Kérvegan, Jean-François (1995), "Les droits de I'homme", en Denis Kambouchner (dir.), Notions de Philosophie, Paris, Gallimard.

Laclau, Ernesto (2009): La razón populista, Buenos Aires, FCE.

Laclau, Ernesto y Mouffe, Chantal (2004): Hegemonía y estrategia socialista. Hacia una radicalización de la democracia, Buenos Aires, FCE.

Lefort, Claude (2004): La incertidumbre democrática, Barcelona, Anthropos.

Macpherson, C. B. (1979): La teoria política del individualismo posesivo, Barcelona, Fontanella.
Montesquieu, Charles de Secondat Baron (1973): Del espiritu de las leyes, Madrid, Porrúa.

Mouffe, Chantal (2000): The democratic paradox, London,Verso.

Rawls, John (1996): El liberalismo político, Madrid, Critica.

- (2001): Justice as Fairness a Restatement, The Belknap Press of Havard University Press.

Rémusat, Charles (1861): "De l'esprit de réaction. Royer-Collard et TocqueviIle", en Revue des Deux Mondes.

Roldán, Darío (2007): Lecturas de Tocqueville, Madrid, Siglo XXI.

Rosanvallon, Pierre (1993): "Histoire du mot démocratie à l'époque moderne", en La Pensée Politique, 1. París, Gallimard-Le Seuil, pp. 11-29.

- (2002): Pour une histoire conceptuelle du politique, Paris, Seuil.

- (2007): La Contrademocracia. La política en la era de la desconfianza, Buenos Aires, Manantial.

Rousseau, Jean-Jacques (1976): El contrato social o Principios de derecho político, Madrid, Porrúa.

Ros, Manuel y Sauquillo, Julián (2005): "Estudio preliminar. Un "sistema penitenciario" traido del viaje". Alexis de Tocqueville y Gustave de Beaumont", en Del sistema penitenciario en Estados Unidos y su aplicación en Francia, Madrid, Tecnos.

Tocqueville, Alexis de (1980): La democracia en América. Vols. 1 y 2, Madrid, Alianza. (De la démocratie en Amérique, Paris, Gallimard, 1968.)

- (1982): Antiguo Régimen y la Revolución. Vols. 1 y 2. Madrid, Alianza. (L'Ancien régime et la révolution, Paris, Gallimard, 1967.)

- (2005): Discursos y escritos políticos, Madrid, Centro de Estudios Políticos y Constitucionales. 